\title{
E SE FOSSE POSSÍVEL DANÇAR PRIMEIRO E PENSAR DEPOIS?
}

Flávia Vieira Santos é doutora em Estudos de Literatura pela PUC-RIO. Email: flavia_vieira11@hotmail.com

\section{Resumo}

O trabalho pretende refletir sobre a expansão do conceito de escrita, para incluir manifestação verbais, visuais, sonoras e performáticas registradas em diferentes suportes materiais ou virtuais.

\begin{abstract}
The present work reflects on an expanded notion of writing, to include sound, verbal, visual, and performance art manifestations, using different media, both material and virtual.
\end{abstract}


Em todos os tempos a escrita, nunca gratuita, respondeu a funções materiais ou espirituais no interior de cada cultura. Refletia assim, em suas metáforas, tanto a imagem da sociedade em sua evolução dinâmica como o papel específico que lhe era atribuído.

Ladislas Mandel

Como rastrear novas formas de escrita num emaranhado de ações, contextos, sistemas, blocos de temporalidade disparatas, discursos e práticas que se definem a partir da expressão "contemporâneo"? Todos os caminhos parecem apontar para a expansão do espectro de atuação dos objetos estéticos, sendo que os mais significativos parecem ser aqueles que se caracterizam por uma permeabilidade cada vez mais acentuada das fronteiras entre os gêneros e os campos do saber. E para os que, de algum modo, se configuram através de processos pautados por uma intensa investigação e experimentação dos meios de expressividade, de divulgação e de receptividade, destacando novas formas de partilha coletiva. Dentro deste novo panorama, torna-se mais adequado considerar "escrita" nos seguintes termos: série de signos construída com elementos de diferentes códigos (verbal, visual, áudio-visual, performático) e registrada em diferentes suportes, sejam eles materiais ou virtuais. Articulando dimensões estéticas, políticas e filosóficas, o que chamamos de "escrita" passa a corresponder à inscrição de percepções, de afetos e também conceitos, e a se comportar como suporte de atividades do corpo e do pensamento.

A permeabilidade atribuída ao que se convenciona chamar "objeto artístico" permite assim, não só uma interferência entre áreas e práticas afins, mas também exige uma reavaliação dos expedientes da crítica diante da inoperância dos critérios avaliativos vigentes a partir do alto modernismo. Em parte, tal inoperância se deve aos pressupostos legados pelas vanguardas históricas, comprometidos com regras fixas, capazes de dar conta dos sistemas estéticos como um todo homogêneo e que se mostram inadequados para os produtos que circulam na cultura contemporânea. Neste sentido, não só as formas de produção de tais objetos bem como os meios de sua circulação reforçam a importância de novos exercícios críticos mais condizentes com os desafios apresentados. A crítica literária e de forma mais ampla a crítica de arte em geral, deverá ser capaz de se confrontar com obras cujo trabalho interpretativo nunca se fecha, daí seu efeito amplamente desestabilizador. Levantadas em movimento transdisciplinar dos terrenos da filosofia, da antropologia e da teoria da comunicação aos dos estudos de 
literatura, as manifestações artísticas na contemporaneidade abordam de um lado, a complexidade da escrita como articulação de elementos codificados por uma partilha coletiva dos saberes e por outro, enfatizam as marcas de experiências corporais que permanecem incodificáveis. Este enfoque, cada vez mais utilizado, é capaz de evidenciar a energia viva transportada pelos signos e, ao mesmo tempo, de romper com a expectativa de plena decodificação (ou tradutibilidade) dos mesmos. Através do resgate dos resíduos e traços de tradições arcaicas na modernidade evidencia-se o papel do corpo, como operador do trânsito que desfaz a dualidade natureza / cultura.

O corpo passa a ser enfocado como materialidade representativa, como superfície na qual se encenam os impasses da situação contemporânea ganhando a centralidade dos debates, seja através de uma abordagem antropológica responsável por elencar as tribos urbanas e seus inúmeros dispositivos de diferenciação/ uniformização, seja através da reabilitação da performance como estratégia artística.

A utilização da performance, meio de expressão muito difundido no contexto cultural da década de 60 ganha novos propósitos de atuação. Não se vincula mais necessariamente à indiscernibilidade dos modos de representação que a caracterizava congregando teatro, música, literatura, vídeo, etc. - mas evoca a transdisciplinaridade dos meios expressivos através de um viés transgressivo. Desse modo, o papel de uma escrita performática tal como é exercida contemporaneamente é o de reconfigurar a transgressão como estatuto próprio do fazer artístico, evidenciando as tensões e os impasses de um mundo em permanente crise, bem como o de questionar a institucionalização hierárquica dos campos de saber.

De algum modo, a recuperação do modelo performático no qual se insere o trabalho da artista portuguesa Vera Mantero, analisado nesta fala, evoca a perspectiva da memória cultural tal como descrita por Giorgio Agamben em seu ensaio Infância e história (Agamben: 2005). Segundo Agamben, a crítica ocidental tende a priorizar uma vertente racionalista do saber em detrimento das dimensões intuitivas, perceptíveis, sensíveis e extra-sensoriais, minimizadas desde a instauração da modernidade. No ensaio, tais práticas são rastreadas na posição proeminente que ocuparam no passado do ocidente (antiguidade, idade média e renascimento, quando astrologia, alquimia, 
hermetismos, possessão, enfeitiçamento contavam como práticas produtoras de saber) e perseguidas no lugar marginal para onde foram empurradas na atualidade. Ao mostrar os desenvolvimentos concorrentes de uma linhagem de pensamento ordenada pela racionalidade consciente e outras que escapam a tal ordenação, o filósofo italiano aponta para a necessidade de se considerar, como atividades simultâneas, tanto a linguagem estruturante da consciência e responsável pela historicização do conhecimento traduzido em códigos, quanto a mudez das experiências do corpo, cuja plena codificação seria inviável mas que, mesmo assim, interviria fundamentalmente na produção do saber. Enfocada na perspectiva da memória cultural, a "infância" situação do in-fans, aquele que não fala, isto é, não domina a linguagem - é um estado que se prolonga por toda a vida, mesmo depois da gradual aprendizagem das línguas e convenções sociais. A experiência muda do corpo, que, no entanto é capaz de comunicar é, justamente, a dimensão de que se busca dar conta quando se propõem estratégias de escrita, na acepção aqui delineada.

Se, como mostra Agamben, os critérios modernos de aceitabilidade da formulação do conhecimento deslocam e desconsideram a experiência do corpo, uma possibilidade de resgate de tais registros é o enfoque da construção de saber por diferentes perspectivas, no caso, com ênfase nas perspectivas de culturas arcaicas, e em manifestações artísticas diferenciadas que se fundamentam em processos intuitivos, mágicos e afins para validar o conhecimento do mundo. Esta vertente ganha aqui um outro contorno, quando associada aos meios de circulação de massa, reforçando o apelo popular do "objeto" bem como sua partilha coletiva, (democratizada), do ponto de vista da recepção. Tal partilha já acena para uma descentralização dos meios de recepção e da crítica, tal como vinha sendo praticada nos centros hegemônicos de sistematização do conhecimento. No entanto, é preciso esclarecer que o tipo de manifestação a que se pretende referir, neste caso, discute também o ato desconstrutor da vanguarda por entender que neste persistiria ainda o componente dicotômico. Nos referidos casos, não se trata mais de substituir a tradição pela ruptura, uma vez que esta já se tornou uma vertente também institucionalizada. Trata-se de atestar a presença de "objetos artísticos" que se destacariam justamente por se apropriar de tradições diversificadas, linguagens múltiplas, de dicções aparentemente díspares, no sentido de privilegiar o paradoxo como matéria de investigação crítica. Esse tipo de escrita encena nos espaços representativos de que dispõe sua condição de linguagem plural, não captável pelos instrumentos críticos convencionais. 
A incorporação do fluxo de informações diversas, de procedências variadas parece ser a matéria fundamental da atuação performática que por sua liberdade de procedimentos e apropriações parece desconsiderar as operações binárias e excludentes evocativas de um cogito cartesiano em favor de uma concepção de arte que encontra na existência "selvagem" sua medida mais justa. Por outro lado, a performance pela intempestividade de sua irrupção traz à luz o conceito deleuziano de acontecimento (événement) como estatuto próprio da linguagem:

\begin{abstract}
Então não se perguntará qual o sentido de um acontecimento: o acontecimento é o próprio sentido. $\mathrm{O}$ acontecimento pertence essencialmente à linguagem, mantém uma relação essencial com a linguagem; mas a linguagem é o que se diz das coisas. Em todo acontecimento, há de fato o momento presente da efetuação, aquele em que o acontecimento se encarna em um estado de coisas, um indivíduo, uma pessoa, aquele que é designado quando se diz: pronto, chegou a hora; e o futuro e o passado do acontecimento só são julgados em função desse presente definitivo, do ponto de vista daquele que o encarna. Mas há, por outro lado, o futuro e o passado do acontecimento tomado em si mesmo, que esquiva todo presente porque está livre das limitações de um estado de coisas, sendo impessoal e pré-individual, neutro, nem geral nem particular, eventum tantum...; ou antes, que não tem outro presente senão o do instante móvel que o representa, sempre desdobrado em passado-futuro, formando o que convém chamar de contra-efetuação. (Deleuze, 2003, 34).
\end{abstract}

O acontecimento encontraria nas "escritas-limite" sua tradutibilidade mais efetiva ao desconsiderar o sujeito como autor do sentido, e refutar a história como ordenação narrativa linear. O intempestivo (o súbito acontecimento) rompe com as noções norteadoras de verdades pré-determinadas tais como sujeito, autoria, narrativa e com a própria noção de história como uma sucessão definida de eventos cronológicos. Este surge, assim, como medida extemporânea de efetuação da escrita. A partir deste ponto de vista, a "performance" (escrita-limite corporal) faz uso de diferentes temporalidades que se aproximam do que poderíamos entender como uma experiência do choque:

O acontecimento se trata, portanto, desta quase-causa, esta determinação vacilante, ávida de sustos. O quase é o desvio, a possibilidade da refração, o tempo em súbitas colisões, neste sentido, é o próprio combate travado contra as determinações. Que quer

Revista Escrita

Rua Marquês de São Vicente, 225 Gávea/RJ CEP 22453-900 Brasil

Ano 2013. Número 16. ISSN 1679-6888.

escrita@puc-rio.br 
dizer então querer o acontecimento? Será que é aceitar a guerra quando ela chega, o ferimento e a morte quando chegam? É muito provável que a resignação seja uma figura do ressentimento, ele que, em verdade, tantas figuras possui. Se querer o acontecimento significa primeiro captar-lhe a verdade eterna, que é como o fogo no qual se alimenta, este querer atinge o ponto em que a guerra é travada contra a guerra, o ferimento, traçado vivo como a cicatriz de todas as feridas, a morte que retorna querida contra todas as mortes. (Deleuze, 2003, 152).

A irrupção do acontecimento no âmbito da linguagem traz a reflexão para o presente, reforçando a experiência do choque. Dessa forma, as manifestações da "escrita-limite" são marcadas pela violência que caracteriza o intempestivo e a instauração de uma nova lógica do sentido. Não se trata de evocar a violência em sua concepção banalizada, tal como apresentada pelo aparato midiático, mas de evocar um tipo de violência específico, capaz de deslocar e mobilizar as bases do pensamento crítico através de dispositivos estéticos que despertem a percepção do receptor, retirando-o de uma zona de conforto. A "escrita-limite" convida o receptor a se tornar parte de um processo maior, que também funciona como partilha coletiva da experiência, como encarnação que supera os limites da arte representativa, para encontrar sua materialidade no corpo do texto, muitas vezes tomado como o próprio corpo do artista.

A abordagem da "escrita-limite", considerando a disparidade de seu domínio e a radicalidade de suas proposições, encontra um denominador comum nos ensaios teóricos evocados acima. Nesse contexto, a obra de Friedrich Nietzsche surge como paradigma da ruptura com a tradição metafísica da filosofia ocidental. Podemos dizer que a conversão do estruturalismo em pós-estruturalismo deve-se à adoção de uma perspectiva neo-nietzschiana por parte de Foucault, Deleuze e Derrida. O impulso desconstrutor da tradição filosófica, divulgado amplamente nos anos sessenta, acompanha a retomada da trajetória de Nietzsche enquanto questionador do conceito de conhecimento como revelação de um nexo objetivo entre o mundo e as palavras que o representariam. Satirizando esta "verdade original", Nietzsche afirma a historicidade de todas as noções e valores, submetidos, assim, ao embate de forças atuantes em cada circunstância. O perspectivismo desenvolve-se com base nessa mesma linha de raciocínio. Ao traçar uma genealogia violenta do conhecimento, o filósofo alia a epistemologia à ética e à política e, ainda, destaca a importância da arte, enquanto produção que exibe sua ficcionalidade, transformando-se na "mais alta potência do

Revista Escrita

Rua Marquês de São Vicente, 225 Gávea/RJ CEP 22453-900 Brasil

Ano 2013. Número 16. ISSN 1679-6888.

escrita@puc-rio.br 
falso". Os desdobramentos do trabalho desconstrutor, característico da genealogia e do perspectivismo nietzschianos, é que propiciam, hoje, o resgate de outros modos de pensamento, exercidos não só em culturas não ocidentais como também através dos dispositivos artísticos independente do suporte. Neste sentido, a recuperação do estatuto da "performance" como arte que aglutina a crise das categorias norteadoras do pensamento acena também para as potencialidades relativas ao corpo.

No ano de 2006, na cidade do Porto, a performer Vera Mantero executa uma improvisação intitulada "O eu podemos dizer do Pierre" por conta das comemorações do Dia Internacional da Dança na qual se propunha a dançar uma fala de Gilles Deleuze. A fala se referia a uma palestra de Deleuze sobre Espinoza a partir do conceito dos três tipos de conhecimento possíveis. O discurso do filósofo pautava-se no primeiro tipo de conhecimento, (aquele que defende o argumento de que quase tudo se movimenta). Pegando este mote e sua incontestável relação com a dança, Vera decide manipular as temporalidades do discurso deleuziano e a partir desse recurso, criar um fundo musical para sua performance. Sobre este processo de trabalho é a própria Vera quem esclarece:

\begin{abstract}
Manipulei as temporalidades do discurso de Deleuze, mas apenas minimamente, porque este já possui temporalidades muito particulares. E baseei o meu movimento na insistência e no grounding, um corpo que pressiona e empurra espaços e vai todo em direcção ao chão. Esta proposta apresenta-se na linha de vários outros trabalhos que tenho feito, em que são propostas, multiplicidades que põem em interacção filosofia e intuição, verbal e não-verbal, racional e irracional. (Mantero, 2006).
\end{abstract}

Ao observarmos a intervenção fica evidente a intenção da artista de associar à fala movimentos e passos de dança incorporando-os aos ritmos de respiração e da fala. A utilização de tais procedimentos além de associar expedientes não verbais à uma escrita verbal, validada pelo arcabouço filosófico desloca a atenção do espectador para o movimento, em sua realização intempestiva. A voz do filósofo, em emissão radiofônica ganha aqui outra função, que não a de reproduzir o conhecimento: ela é música para os movimentos da performer. Este gesto inaugura um novo tipo de experiência artística pautada agora, em uma outra partilha coletiva. Este deslocamento faz com que o que está sendo exposto e ensinado através da palestra, no idioma francês, passe a ser enfocado apenas através do gesto (com a musicalidade expressa pela voz do filósofo) que se torna cada vez mais potente, desconsiderando não só o que está sendo dito, como

Revista Escrita

Rua Marquês de São Vicente, 225 Gávea/RJ CEP 22453-900 Brasil

Ano 2013. Número 16. ISSN 1679-6888.

escrita@puc-rio.br 
o idioma em que está sendo proferido. A busca do sentido se dá através dos movimentos da artista que trazem da fala um tipo de matéria sonora com a qual se constrói o gesto. Por isso, é preciso incorporar ao gesto todos os mínimos expedientes proporcionados pela entonação. A coreografia da artista reivindica desse modo, uma nova construção dos significados apresentados na fala deleuziana que diluem-se paulatinamente dando lugar ao conjunto de movimentos reveladores da dança. O giro estabelecido é o que faz o trabalho de Vera Mantero realizar uma transição eficaz entre a escrita codificada e partilhada coletivamente através do arcabouço filosófico para a dança, que passa a se configurar como escrita que, uma vez encenada, desconsidera todo o conhecimento prévio, codificado. Tal estratégia faz referência àquela matriz sensorial e intuitiva referida por Agamben, e corrobora os gestos corporais como dispositivos de uma experiência ímpar vivenciada pelo corpo que dança. $O$ movimento de Vera se caracteriza mais enfaticamente por se opor àquele saber institucional que se desconstrói através dos movimentos do corpo. E por propor, do ponto de vista da recepção, uma outra vivência artística. A performance de Vera Mantero articula e funda assim uma nova partilha do saber a partir deste deslocamento que passa a validar o conhecimento por uma escrita exclusivamente corpórea, tomando partido da filosofia e dando a ela uma nova acepção. Este trânsito cria um novo traço que se estabelece a partir dos movimentos da artista acompanhando a errância do pensamento em suas assertivas, seu repouso, em seus traços de respiração e de voz. Assim, o traço, o movimento em seu fluxo em circuitos heterogêneos compostos por respiração, pausa e movimento transformam as palavras em ação, garantindo completamente a eficácia da recepção do público. A performance de Vera Mantero recria assim, em sua especificidade, e a partir de uma escrita verbal os componentes evocativos de uma experiência muda do corpo que, ao desconsiderar os elementos de uma escrita codificada e partilhada coletivamente recupera uma dimensão ancestral e intuitiva da experiência corporal, que no entanto continua a comunicar. $\mathrm{O}$ ato performático, neste caso, oferece simultaneamente um novo estatuto dos rastros e das marcas da vivência corpórea a partir de uma nova concepção de escrita que passa a incorporar como signos potentes: os ritmos da voz, os regimes de respiração, a ênfase correspondente ao gesto e ao movimento, em prol agora de uma nova concepção de conhecimento e saber. Tais expedientes exigem dispositivos de avaliação irredutíveis à lógica verbal, embora partam de uma escrita (de uma fala) e façam referência à ela, de maneira corrosiva. Ao fundar uma nova forma de partilha coletiva, aquele conhecimento - o arcabouço filosófico referido pelo filósofo pretensamente detentor do saber - é parodicamente desconsiderado, indo literalmente "ao chão". A performer se desvencilha desta escrita canônica em nome de uma "outra" escrita. Esta "outra" escrita, se faz necessária enquanto um caminho teóricometodológico que põe em evidência novas perspectivas e rumos para a arte. A dança que encena o gesto reforça a diferença, a rasura em cima da fala, expediente 
indispensável para evitar a crescente padronização de um olhar comum por parte de um aparato crítico. A performance de Vera Mantero funda dessa maneira um outro território conceitual. Ao definir a escrita performática como deflagradora de uma experiência limite colocando em xeque não só os processos de acumulação como os de hierarquização do saber é preciso reivindicar também a importância de um estado de crise, traduzida pela intempestividade do movimento e da performance que ocorre em uma data aleatória e sem ensaio prévio, invalidando completamente a reprodução do ato. Neste sentido, o corpo se coloca como antagonista de um processo acumulativo do saber encenado na fala do filósofo. A sabedoria do corpo provém, por outro lado, de uma vertente sensorial, sensível, que evoca dimensões arcaicas de conhecimento intuitivo, invalidadas pelos processos de compartimentação do saber. Esta sabedoria muda traz à tona todos expedientes selvagens e não codificados, que interferem na produção do conhecimento e na fundamentação de uma nova forma de escrita. $\mathrm{O}$ corpo da performance torna-se assim, literalmente, o próprio corpo do texto, superfície onde se inscrevem os signos e os questionamentos observados na contemporaneidade. Ele revela seu papel de catalizador do pensamento, tornando-se o próprio dispositivo no qual a arte pode estar encarnada. Neste movimento, o papel da escrita corporal aglutina de maneira consistente as formas diversificadas dos saberes, no sentido de construir efetivamente uma "escrita-corpo":

O papel da escrita é construir, com tudo o que a leitura construiu, um corpo (quicquid lectione collectum est, stilus redigat in corpus). E, este corpo, há que entendê-lo não como um corpo de doutrina, mas sim - de acordo com a metáfora tantas vezes evocada da digestão - como o próprio corpo daquele que, ao transcrever as suas leituras, se apossou delas e fez sua a respectiva verdade: a escrita transforma a coisa vista ou ouvida em forças e em sangue (in vire, in sanguinem). (Foucault, 2004, p. 152).

O movimento de construção do corpo apontado por Foucault evoca não só uma vertente vitalista da arte, mas também remeteria às perspectivas alternativas de produção de saber, que encarnadas no corpo aludem à apropriação de instrumentos especulativo-críticos de fontes diversas. Este argumento encontra apoio e reforço nas mais recentes publicações do antropólogo Eduardo Viveiros de Castro. Formado no estruturalismo de Claude Levi-Strauss, o antropólogo brasileiro encaminhou seu trabalho na direção do pós-estruturalismo, em particular na versão deleuziana, na contramão da maioria de seus colegas. Cabe acrescentar que o trabalho atual de Viveiros de Castro vai ao encontro da chamada "antropologia simétrica", vertente liderada por Bruno Latour, cujo principal propósito é estudar as instituições do ocidente

Revista Escrita

Rua Marquês de São Vicente, 225 Gávea/RJ CEP 22453-900 Brasil

Ano 2013. Número 16. ISSN 1679-6888.

escrita@puc-rio.br 
moderno de forma integrada, seguindo os parâmetros da etnografia das sociedades selvagens. Empenhado em desconsiderar a compartimentação disciplinar, "reatando o nó górdio" das redes de saber, Latour questiona as bases da epistemologia para desconstruir o privilégio garantido às ciências, como detentoras da verdade fundada em critérios de racionalidade e pureza. É, portanto, em trajetória própria, mesmo entre seus pares da nova tendência da antropologia, que Viveiros de Castro, exercitando travessias interdisciplinares, passou a articular seus registros etnográficos à maneira perspectivista delineada pelas análises de Latour e pela radicalidade de Deleuze e Guattari, enquanto críticos da perspectiva ocidental. O exemplo de Viveiros de Castro, ao transitar entre orientações teórico-metodológicas para fazer de suas tarefas antropológico-filosóficas um empreendimento de abertura de horizontes para o pensamento, deve guiar esta pesquisa em seu exercício de atualizar o conceito de "ato performático" e torná-lo um operador de leitura capaz de extrair de amostras da escrita performática uma argumentação consistente em relação ao fluxo e a troca incessante como mecanismos de perpetuação dos saberes. Troca esta, desde sempre observada nas sociedades primitivas:

Talvez, porém, para sociedades cujo (in)fundamento é a relação aos outros, não a coincidência consigo mesmas, nada disso faça o menor sentido: As narrativas de contato e mudança cultural têm sido estruturadas por uma dicotomia onipresente: absorção pelo outro ou resistência ao outro. (...) Mas, e se a identidade for concebida, não como uma fronteira a ser defendida, e sim como um nexo de relações e transações no qual o sujeito está ativamente comprometido? A narrativa ou narrativas de interação devem, nesse caso, tornar-se mais complexas, menos lineares e teleológicas. O que muda quando o sujeito da história não é mais ocidental? Como se apresentam as narrativas do contato, resistência ou assimilação do ponto de vista de grupos para quais a troca, não a identidade, é o valor fundamental a ser afirmado? (CASTRO: 2002, 195).

A performance, como escrita corporal é responsável pela transformação da coisa vista, ou ouvida, neste caso, em movimento vivo. Ela remete, como estratégia de reflexão, às perspectivas alternativas de produção de saber, que encenadas continuam a aludir à apropriação de instrumentos especulativo-críticos de fontes diversificadas. Uma dessas fontes é a própria dança que integra-se ao pensamento contemporâneo como vertente de investigação crítica. Em um trabalho anterior, do ano de 1991, e intitulado "Talvez ela pudesse dançar primeiro e pensar depois". Vera Mantero recupera a sentença becketiana "Dance first. Think later. It's the natural order" dando-lhe uma interpretação particular, numa síntese pautada no trânsito livre do movimento, que busca recuperar um estágio de quase inconsciência, cito: 
Disse-o repetidamente, a propósito da peça: "A minha relação com a dança gira à volta das seguintes questões: o que é que a dança diz? o que é que eu posso dizer com a dança? o que é que eu estou a dizer quando estou a dançar?". E a origem de «Talvez ela pudesse dançar primeiro e pensar depois» está, precisamente, nessa busca. Criada em 1991, em pleno surgimento do movimento Nova Dança Portuguesa, a peça foi pensada para o festival Klapstuck, na Bélgica, e caracteriza-se por uma explosão do movimento, aparentemente sem controle. Mas, na verdade, trata-se da construção de uma fluidez (se é que tal é possível), da procura de um outro estado, quase de inconsciência, onde o corpo possa existir livre.(Mantero, 2006).

Em busca de reconstruir uma fluidez impensável por meio de uma escrita verbal, o corpo da performance reforça sua competência para estar inteiramente livre no fluxo contínuo da dança. Neste estágio avançado de consciência às avessas, o corpo desconstrói positivamente os precedentes de uma filosofia que se pretende detentora do conhecimento em suas formas limitadas de apresentação. A performance não deixa de evocar assim a filosofia do corpo dançarino, do corpo "em estado de dança" que fundamenta o sentido em apenas um átimo de segundo. A associação da dança com a filosofia remete ao pensamento nietzcheano, tal como apresentado no seguinte trecho:

\begin{abstract}
Cantando e dançando, o homem se manifesta como membro de uma comunidade superior: ele desaprendeu a caminhar e falar e está a ponto de, dançando, voar pelos ares. Seus gestos revelam uma encantadora beatitude. Assim como agora os animais falam e a terra produz leite e mel, também a voz do homem ressoa como algo de sobrenatural: ele se sente um deus; agora seu andar é tão nobre e cheio de êxtase como aquele dos deuses que viu em seus sonhos. O homem não é mais artista, tornou-se obra de arte: a potência estética da natureza inteira, para a máxima satisfação do Um primordial, se revela aqui sob o estremecimento da embriaguez. A argila mais nobre, o mármore mais precioso, o homem aqui é moldado e trabalhado. (NIETZSCHE: 2007, p.31).
\end{abstract}

A performance e numa esfera mais geral todo o trabalho de Vera Mantero cumpre assim seu objetivo de TRANS- ferir os códigos não verbais para uma outra esfera de significação. A recuperação da experiência muda do corpo que fundamenta novos tipos de sentido converte-se num ponto de partida para um estágio de quase 
"inconsciência" onde o corpo passa a existir em liberdade, conservando-se "no hiato entre as coisas inteligíveis", de acordo com a definição da artista plástica Laura Lima. É neste hiato que podemos alocar o tipo de experiência proporcionada pelo trabalho de Vera Mantero em seu esforço de questionar de forma inquietante os pilares de uma escrita convencional. Na respiração e na pausa, aí se encontra o saber. Só dançando primeiro e pensando depois é possível viver satisfatoriamente o contemporâneo.

\section{REFERÊNCIAS BIBLIOGRÁFICAS:}

AGAMBEN, Giorgio. Infância e história. Belo Horizonte: Ed. UFMG, 2005.

BAUMAN, Zygmunt. Modernidade e ambivalência. Rio de Janeiro: Jorge Zahar, 1999.

CASTRO, Eduardo Viveiros de. A inconstância da alma selvagem. São Paulo: Cosac Naify, 2002.

DELEUZE, Gilles. Lógica do Sentido. São Paulo: Perspectiva, 2003.

. Nietzsche e a filosofia. Rio de Janeiro: Ed. Rio, 1976.

FOUCAULT, Michel. A Escrita de si. Ditos e escritos. Rio de Janeiro : Forense, 2004.

MANDEL, Ladislas. Escritas - espelho dos homens e das sociedades. Tradução de Constância Egrejas. São Paulo: Rosari, 2006.

MANTERO, Vera. In.: http://www.orumodofumo.com/, Entrevista, 2006.

NIETZSCHE, Friedrich. NIETZSCHE, Friedrich. O Nascimento da Tragédia. São Paulo: Escala, 2007.

ONFRAY, Michel. A Potência de Existir. São Paulo: Martins Fontes, 2010. 